\title{
Correction to: The economic costs of loneliness: a review of cost-of-illness and economic evaluation studies
}

\author{
Cathrine Mihalopoulos ${ }^{1}\left({ }^{10} \cdot\right.$ Long Khanh-Dao Le $^{1} \cdot$ Mary Lou Chatterton ${ }^{1} \cdot$ Jessica Bucholc ${ }^{1}$. \\ Julianne Holt-Lunstad ${ }^{2,3}$ - Michelle H. Lim ${ }^{3}$. Lidia Engel ${ }^{1}$
}

Published online: 21 August 2019

(c) Springer-Verlag GmbH Germany, part of Springer Nature 2019

\section{Correction to: Social Psychiatry and Psychiatric Epidemiology https://doi.org/10.1007/s00127-019-01733-7}

The article, "The economic costs of loneliness: a review of cost_of_illness and economic evaluation studies", written by Cathrine Mihalopoulos was originally published electronically on the publisher's internet portal (currently SpringerLink) on 22 May 2019 with open access.

With the author(s)' decision to step back from Open Choice, the copyright of the article changed on June 2019 to (C) Springer-Verlag GmbH Germany, part of Springer Nature 2019 and the article is forthwith distributed under the terms of copyright.

The original article was corrected.

The original article can be found online at https://doi.org/10.1007/ s00127-019-01733-7.

Cathrine Mihalopoulos

cathy.mihalopoulos@deakin.edu.au

1 Deakin University, Locked Bag 20001, Geelong, VIC 3220, Australia

2 Psychology Department, Brigham Young University, 1001 KMBL, Provo, UT 84602, USA

3 Centre for Mental Health, Iverson Health Innovation Institute, Swinburne University of Technology, Level 10, ATC Building, Hawthorn, VIC 3122, Australia 